\title{
А.В. Пчелинцев
}

\section{КОМПОЗИЦИОННЫЕ МЕТОДЫ АРАНЖИРОВКИ В КОНТЕКСТЕ СОВРЕМЕННЫХ НАПРАВЛЕНИЙ АНСАМБЛЕВОГО ИСПОЛНИТЕЛЬСТВА НА НАРОДНЫХ ИНСТРУМЕНТАХ}

\begin{abstract}
В статье исследуются тендениии, сложившиеся в настоящее время в сфере ансамблевого исполнительства на народных инструментах и нашедшие отражение в композиционных методах аранжировки. Отмечается, что аранжировка, став самостоятельным видом творчества, выдвигает проблему профессионализации подходов в работе с первоисточником. Раскрываются основные особенности современной трактовки народных инструментов в сфере ансамблевого исполнительства. Это их дальнейшая академизация, обладающая значительным потенциалом для развития всего спектра выразительных средств, и, напротив, упрощенная трактовка народных инструментов в духе эстетики скоморошества, предполагающая применение в аранжировке примитивных решений.

Ключевые слова: аранжировка, домра, балалайка, интонационное переосмысление, скоморошество, массовая культура, музыкальный перформанс.
\end{abstract}

Аранжировка как самостоятельный вид музыкального творчества заняла прочное место в практике сольного и ансамблевого исполнительства на народных инструментах. Процессы, наметившиеся в этой сфере во второй половине ХХ в., получили продолжение и интенсивное развитие в текущем столетии. Главной проблемой в данной области остается профессионализация методов аранжировки, что делает актуальным обращение к анализу тенденций, сложившихся к настоящему времени. Здесь можно выделить несколько направлений, ставших импульсом для формирования композиционных методов аранжировки в сфере ансамблевого исполнительства.

Первое из направлений отражает развитие академической направленности в трактовке народных инструментов. С ним связана деятельность таких коллективов, как «Русская мозаика» (1979), «Русский фестиваль» (1989), «Московский квартет» (1997). Эти ансамбли, в разное время руководимые выдающимся домристом и композитором А. Цыганковым, исполняли произведения русской и зарубежной классики, современную эстрадную и джазовую музыку. Частично к этому направлению можно отнести ансамбль «Терем-квартет» (1986), если говорить об обращении коллектива только к классической музыке, так как в большинстве случаев творчество ансамбля представляет собой стилевой сплав классики, джаза и фолк-рока.

Ансамблевое народно-инструментальное эстрадное исполнительство взрастило многие профессиональные коллективы, на этой почве дали ростки опыты интерпретации академических народных инструментов в новой и непривычной для них среде - эстрадно-джазовой музыке, сформировались основные принципы аранжировки для таких составов. Благодаря возможности, связанной с тембровой персонификацией инструментария, многочисленности темброво-регистровых комбинаций, погружению, например, в сферу джазо- 
вой интонационности или звуковую среду музыки внеевропейской традиции, данное направление музыкально-исполнительской деятельности обладает способностью давать порой уникальный художественный результат.

Одним из ярких примеров может служить творческая деятельность квартета «Сказ». Ансамбль рассматривает аранжировку как главное выразительное средство, причем такой подход находит отражение в композициях самых разных жанровых групп. К ним относятся: популярная классическая музыка, оригинальные сочинения, обработки русских народных мелодий, популярная музыка стран мира, городские романсы, регтаймы. В каждой категории квартет находит свои выразительные средства аранжировки. Общим знаменателем для них является тонкая передача образности исполняемой музыки, изобретательность приемов исполнения при использовании традиционных для народных академических инструментов фактурных способов разработки материала. Среди подлинных находок следует отметить аранжировку композиции «Feeling» А. Морриса с ее предельно точной передачей лирической образности темы, выполненной pizzicato vibrato у солирующей домры на фоне триольного фона балалайки таким же приемом, с постепенным подключением аккордового заполнения, гибкого сочетания приемов тремоло и пиццикато, одноголосного и аккордового изложения темы. В этом же ряду можно назвать обработку романса «Я встретил вас», тонкая звуковая картина которой удивительно точно написана с помощью тщательно продуманных приемов звукоизвлечения при каждом новом проведении темы на фоне филигранных фигур аккомпанемента. И таких примеров в репертуарной палитре немало.

Однако наиболее интересной представляется работа в области совмещения инонациональных элементов в звуковом поле академических народных русских инструментов. Опыт интерпретации иранской (персидской) народной музыки, закрепленный в CD-альбоме квартета «Сказ» («Чай из самовара», 2017 г.), оказался вполне успешным благодаря тембровой идентичности русских и иранских музыкальных инструментов. Говорить об их родстве позволяет принадлежность, в соответствии с общепринятой научной классификацией музыкальных инструментов Хорнбостеля-Закса, к группе струнных щипковых (хордофонов). Но это - их самое общее сходство, лежащее на поверхности. Точек соприкосновения при сравнении органологических признаков русского и иранского инструментария значительно больше, особенно в конструктивном плане.

В состав квартета «Сказ» входят домра малая (прима), домра-альт, балалайка-прима, балалайка-бас. В соответствии с одной из версий, считающейся в наше время основной [1. С. 18], домра имеет восточное происхождение. Впервые эта версия была выдвинута А.С. Фаминцыным, одним из основоположников исторического изучения народной музыки в России. Его предположение о том, что родоначальником русской домры является древний струнный щипковый инструмент - арабо-персидский танбур (тамбур), было основано на сходстве конструкции инструментов и способов звукоизвлечения: «Домра < ..> должна была иметь корпус круглого или овального очертания, плоский со стороны струн и выпуклый с противоположной стороны, сравнительно длинную шейку и две струны; играли на домре, при том же условии, вероятно, не прямо пальцами, а плектром (тросточкой, щепочкой, 
перышком) <..>» [2. С. 366]. Домра родственна не только танбуру (тамбуру) как более древнему арабо-персидскому инструменту, но и тару, считающемуся одним из наиболее важных в современной иранской музыке инструментов. Как и домра, тар - инструмент плекторный, звук на нем извлекается с помощью плектра, изготовленного из рога. Тар также насчитывает несколько разновидностей (сопрановую, альтовую и басовую). У обоих инструментов на грифе есть лады. Если на домре они жестко связаны с грифом, то у иранского тара - 22 основных навязных ладка и 2-3 дополнительных камышовых, наклеенных у корпуса. Основные лады фиксируются вставными деревянными колышками, находящимися в специальном желобке шейки.

Другой персидский народный струнный щипковый инструмент - сетар имеет в свою очередь сходство с балалайкой (не считая характерную треугольную форму). Ее корпус склеивается из отдельных сегментов, корпус сетара - также из полосок тутового дерева. Гриф балалайки снабжен металлическими ладами, гриф сетара - навязными. Характерно, что и у балалайки до конца ХІХ в. было 5-7 навязных ладов. Сходны и приемы звукоизвлечения, но с некоторым отличием: если основным приемом игры на балалайке является бряцание, выполняемое указательным пальцем правой руки попеременным движением кисти вверх-вниз, то на сетаре играют большим и указательным пальцами, причем правая рука на сетаре не ударяет сверху по струнам, а, напротив, защипывает струну снизу длинным ногтем указательного пальца, создавая при этом специфическую звуковую атаку, сходную с ударом плектра, но более мягкую. Если о тембровом подобии русских и персидских народных инструментов по органологическим признакам говорить вполне уместно, то в интонационном отношении сходство достаточно отдаленное: подвижность ладков на таре и сетаре обусловлена особенностями строения макама - ладово-мелодической модели с элементами микрохроматики, что не соответствует европейской системе темперированного строя. Из вышеизложенного очевидно преобладание сходства по внешним признакам. Тем не менее органологическая идентичность, проявляющаяся в «обобщении через тембр», позволяет смело экспериментировать с иранской мелодикой, не вторгаясь в микрохроматику макама. Если гипотетически представить обратный процесс взаимодействия национального инструментария, то окажется, что у иранских инструментов больше возможностей интерпретации народной русской музыки: для этого достаточно зафиксировать лады на грифе в позиции, отвечающей европейской темперированной системе.

Попытка тембровой интерпретации иранских народных инструментов на домрах и балалайках стала смелым шагом квартета «Сказ». Аранжировку образцов иранской (персидской) народной музыки для квартета «Сказ» выполнил Кейван Садра, музыкант иранского происхождения. Вот несколько примеров. В композиции «Kuhestan» аранжировщиком предпринята удивительно тонкая попытка соединить одними «узами» иранскую народную мелодию и русскую протяжную песню. Собственно, «почти» в нее и превратился иранский первоисточник. Его гармонизация выполнена вполне «европейскими» средствами, такими, как ладовое колорирование, применение трезвучий побочных ступеней, элементов ленточного голосоведения и др. Интонационная трансформация, попытка интонационного переосмысления звуковой идентичности народной иранской музыки совершенно естественно 
рождает новый интонационный смысл, ставший возможным благодаря своеобразному «обобщению через тембр» - обобщению через тембровую идентичность народного русского и народного иранского инструментария.

Композиция «Неу Yaar Hеy Yaаr» в большей степени наделена национальным иранским колоритом. Выразить его аранжировщику удается ладовыми средствами благодаря опоре на низкую вторую ступень. «Кружение» пунктирной ритмики трихордных попевок, проходящее через всю пьесу, почти зримо воссоздает атмосферу иранского народного танца. Минимальное использование тремоло домры или приема «бряцание» балалайки и преобладание одиночных ударов pizzicato у этих инструментов выводят на первый план имитацию звукоизвлечения на народных иранских инструментах и создают акустически точную звуковую картинку.

Другое направление в сфере ансамблевого исполнительства, развивающееся с 80-х гг. XX в. и вплоть до настоящего времени, напрямую связано с древним пластом русской культуры - скоморошеством, получившим на Руси широкое распространение в XV-XVII вв. Вероятно, деятельность скоморохов можно рассматривать как своеобразную субкультуру, а их самих - носителями смеховой культуры, имевшей распространение и в Европе (например, жонглеры, шпильманы). Скоморохи представляли массовое искусство того времени и «были проводниками особого мироощущения народной праздничности» [3. С. 164]. Их искусство как явление фольклорного типа было легкодоступным для восприятия, востребованным и демократичным и при всей своей незатейливости, простоте и примитивности несколько столетий оставалось для народа формой досуга, развлечений, вполне способной заменить ему новейшие сценические зрелища или новейшую литературу. Творчество скоморохов имело свои культурные традиции, новаторски воплощенные в массово-демократических музыкальных, театральных и литературных видах и жанрах. По определению В. Конен, это «самостоятельный, несмотря на его раздробленность, художественный пласт, представленный своими собственными видами и жанрами, которые чаще всего живут в демократических кругах и не совпадают по своим фундаментальным признакам с двумя другими пластами музыки» [4. С. 34].

Основные черты искусства скоморохов - шутовство, пародия, сатира, издевка, пересмешничество, циркачество, «смехотворчество», «глум», танцы, игры, балагурство, лицедейство - нашли прямое отражение в современной массовой культуре и ее частном проявлении - ансамблевом исполнительстве на народных инструментах. Одной из первых на этом поприще в середине 80-х гг. прошлого века стала экцентрик-шоу-группа «Джаз-балалайка». Название ансамбля выявляет лишь эксцентричную, но не парадоксальную сущность. Никакого парадокса в том, что на балалайке или домре сегодня совершенно профессионально исполняют джаз, нет. В этом смысле абсолютно справедливым и пророческим является мнение о том, что «инструментарий сам по себе еще не является определяющим фактором джазовой специфики <..> и что элементы джаза можно встретить у исполнителей на примитивных музыкальных инструментах, таких, как уошборд, губной гармонике, казу или паре сковород» [5. С. 179]. Созданный в начале 90-х гг. прошлого века ансамбль «Джаз-экспромт» как антипод ансамбля «Джаз-балалайка» убедительно доказал универсализм академических народных инструментов - домры и бала- 
лайки и способность аутентично исполнять на них самые сложные джазовые композиции. В соответствии же с эстетикой экцентрик-шоу-группы «Джазбалалайка» в репертуар ансамбля входят лишь пародии на музыку всех времен и народов. В исполнении группы звучат мелодии популярной классики, джаз, фольклор, рок-н-ролл, артисты лицедействуют, поют и танцуют, сменяя музыкальные инструменты и сценические костюмы.

Весь этот незатейливый перформанс в духе эстетики скоморошества определенным образом отразился и на средствах аранжировки экцентрикшоу-группы «Джаз-балалайка». Фольклорная основа группы проявляется через внешние признаки, связанные лишь с использованием балалайки как устойчивого в сознании потребителей массовой культуры символа подлинно национального искусства. Апелляция к упрощенным вкусам широкой аудитории, не отягощенной представлениями о ценностных ориентирах, и не предполагает какое-либо серьезное отношение к конечному продукту аранжировке композиций, где на первый план выходят виртуозничество и установка на внешние эффекты. Отсюда - достаточно простые инструментальные решения, подчиненные одной лишь цели: подчеркнуть парадоксальность сочетания несочетаемого, вызывающего, по замыслу авторов аранжировок, комический, шутовской эффект.

Значительно дальше по пути шоу-бизнеса пошел еще один представитель данного направления ансамблевого исполнительства в духе эстетики скоморошества - шоу-оркестр «Русский стиль», который позиционирует себя как «новый формат музыкального перфоманса». За этим стоит исключительно коммерческий проект. Репертуар оркестра насыщен эклектичным сочетанием «музыки всех времен и народов», это - классика, рок-н-ролл, фолк, мѐтал, рок, джаз и т.п. В эстетическом плане идея далеко не новая, подобные устремления берут свое начало от санкт-петербургского «Терем-квартета» или экцентрик-шоу-группы «Джаз-балалайка». Основу ансамбля составляют домры и балалайки, два баяна, гусли. Все инструменты имеют индивидуальную подзвучку и радиосистему. Это необходимо для общего звукового баланса, так как в оркестр входит также ударная установка и расширенный набор перкуссии. Каждый номер обязательно сопровождается незатейливой хореографией, являющейся непременным атрибутом сценического действа. Оставляя в стороне эстетическую сущность, свойственную данному продукту массовой культуры, следует подчеркнуть особенность, отличающую шоуоркестр «Русский стиль», например, от экцентрик-шоу-группы «Джазбалалайка» или ей подобных. Это - обращение к одному из пластов массовой культуры современности - рок-музыке и ее жанровым разновидностям.

Интерпретация рока на русских народных инструментах - шаг очень смелый и не бесспорный. Воплотить его технически, учитывая их ограниченные динамические возможности, стало возможным благодаря уплотнению «звуковой массы» за счет количества исполнителей. Существенная коррекция потребовалась также и в средствах аранжировки. Ее приемы достаточно однотипны и отражают общеэстетические характеристики рока. Как правило, это проведение основного мелодического элемента - тяжелого «риффа» - в исполнении унисона домр и балалаек, имитирующих перегруженный, «тяжелый» звук электрогитары, являющейся центральным элементом мѐтала. Мелодическая надстройка, максимально подчеркивающая частотными характе- 
ристиками нижнюю середину и верх, поддерживается плотной ритм-секцией: здесь это контрабас-балалайка и расширенная группа ударных. Мощь и насыщенность низкочастотности в ритм-секции достигаются тем, что контрабас-балалайка дублирует бит на бас-бочке. Отличие от первоисточника состоит в отсутствии вокала, хотя и в большинстве оригинальных композиций хард-рока в целом вокал, как правило, подчиняется общему звучанию группы, где центральную роль все же играет гитарист. Типичным примером может служить композиция «Thunderstruck» в исполнении группы AC/DC: здесь обращает на себя внимание ситуация двойного лидерства - вокалиста и гитариста. В интерпретации же шоу-оркестра «Русский стиль» из композиции взята только инструментальная надстройка, создающая остинатный фон для действа, которое в соответствии с эстетикой рок-музыки помимо музыкального компонента вбирает в себя и визуальный ряд: в исполнение вовлекаются зрители из зала, которых за полминуты обучают ритмично и синхронно с оркестром извлекать на балалайке простейшую звучность.

В интерпретации композиции «Smells Like Teen Spirit» (рок-группа «Nirvana») шоу-оркестр «Русский стиль» использует характерные признаки гранжа. Этот поджанр альтернативного рока, развившийся из хардкор-панка в середине 1980-х гг., отличает «грязное» гитарное звучание, обилие дисторшна и контрастная - по принципу «громко - тихо» - динамика. Поскольку в шоу-оркестре «Русский стиль» вокал не применяется, то свойственные гранжу мрачные тексты на тему отчуждения, одиночества и апатии отсутствуют. Это компенсируется эпатажностью поведения самих музыкантов, наличием атрибутики панк-культуры (характерные прически, вызывающая одежда, кеды) и наличием на электробалалайке звукового эффекта, достигаемого искажением сигнала путем его «жесткого» ограничения по амплитуде, т.н. «дисторшн».

Еще больше возможностей для осуществления перформанса во время исполнения образцов рок-музыки шоу-оркестр «Русский стиль» видит в обращении к стилистике британской группы «Blur», представляющей собой смесь таких поджанров, как альтернативный рок, брит-поп, инди-рок, дэнсрок и альтернативная танцевальная музыка. В композиции «Song 2» мотивация сценического поведения диктуется намеками «на грани», за которую, впрочем, никто и не переходит. Музыкальное содержание отходит здесь на второй план, приемы аранжировки лишь подчеркивают отдельные элементы характерного рок-саунда, например, форсированное аппаратными средствами соло контрабас-балалайки.

Жесткое киберпанковское звучание достигается в интерпретации композиции «Voodoo People» (группа «Prodigy»). Смесь элементов различных стилей - рейва, хардкор-техно, индастриала, брейкбита, электронного рока с элементами панка, типичных для британской группы, находит совершенно несвойственное отражение в звуковой палитре шоу-оркестра «Русский стиль». Парадоксальность сочетания рок-музыки в тембровом воплощении народными струнными инструментами усиливается вторжением трансформированной цитаты из танго «La Cumparsita» (M. Родригес, 1915), интонации которого искусно вытекли из «Voodoo Рeople». Не осознавая того, аранжировкой этой композиции достигается кинематографический эффект, основанный на принципах монтажа. 
Таким образом, одна из линий ансамблевого исполнительства в трактовке народных инструментов связана с развитием академической направленности. Наглядным примером здесь может служить творческая деятельность квартета «Сказ». Он одним из первых начал поиски новых средств выразительности на академических народных инструментах, что нашло отражение в приемах аранжировки во всех жанровых группах - обработках популярной классической музыки, оригинальных сочинениях, обработках русских народных мелодий, популярной музыки стран мира, городских романсов, регтаймах. Главным средством тонкой передачи образного строя исполняемой музыки в них является темброво-регистровая палитра, оригинальные фактурные находки и использование широкого спектра приемов звукоизвлечения. Важным средством расширения выразительных возможностей аранжировки стали опыты по нахождению тембровой идентичности народных инструментов - русских и иранских. Это выразилось в интонационном переосмыслении фольклорного персидского первоисточника при помощи спектра приемов европейского типа - ладового колорирования, ленточного голосоведения, перегармонизации интонаций на основе переменности побочных ступеней. Наряду с этим применяется имитация звукоизвлечения народных иранских инструментов и попытки реконструкции ладово-мелодической модели макама.

Другое направление в сфере ансамблевого исполнительства напрямую связано с древним пластом русской культуры - скоморошеством, получившим на Руси широкое распространение в XV-XVII вв. В соответствии с эстетикой этого феномена национальной культуры в настоящее время усвоены лишь его внешние очертания. Русские народные инструменты используются как устойчивые в сознании потребителей массовой культуры символы народного музыкального искусства, в чем проявляются признаки спекуляции ценностями подлинно народной культуры. Такой подход отразился и на средствах аранжировки, где на первый план выходят виртуозничество и установка на внешние эффекты. Это предполагает применение достаточно примитивных инструментальных решений. Во главе всех псевдохудожественных решений стоит коммерциализация, а не «новый взгляд» на русские народные инструменты, как это декларируется адептами этого направления.

\section{Лuтература}

1. Шарабидзе К.Б. Современные проблемы обучения игре на народных музыкальных инструментах : теория и практика (на материале учебно-воспитательной работы в классе домры) / дис. ... канд. пед. наук. М., 2012. 210 с.

2. Фаминцын А.С. Домра и сродные ей музыкальные инструменты русского народа. 2-е изд. // Скоморохи на Руси. СПб. : Алетейя, 1995. С. 315-535.

3. Белкин А.А. Русские скоморохи. М. : Наука, 1975. 194 с.

4. Конен В.Дж. Третий пласт: новые массовые жанры в музыке XX века. М. : Музыка, 1994. $160 \mathrm{c}$.

5. Сарджент У. Джаз: Генезис. Музыкальный язык. Эстетика. М. : Музыка, 1987. 294 с.

Anatoly V. Pchelintsev, Moscow State Institute of Music named after A.G. Schnittke (Moscow, Russian Federation).

E-mail: a.v.pchelintsev@mail.ru

Vestnik Tomskogo gosudarstvennogo universiteta. Kul'turologiya i iskusstvovedeniye - Tomsk State University Journal of Cultural Studies and Art History, 2019, 34, pp. 149-156.

DOI: $10.17223 / 2220836 / 34 / 15$ 
COMPOSITIONAL METHODS OF ARRANGEMENT IN THE CONTEXT OF MODERNDIRECTIONS OF ENSEMBLE PERFORMANCE ON FOLK INSTRUMENTS

Keywords: arrangement; domra; balalaika; intonational rethinking; buffoonery; mass culture; musical performance; rock music.

The article examines the trends that have developed in the field of ensemble performance on folk instruments and are reflected in compositional methods of arrangement. It is noted that the arrangement, becoming an independent kind of creativity, close to the composer, raises the problem of professionalization of approaches in the work with the original source. The main features of modern interpretation of folk instruments in the field of ensemble performance are revealed. One of the lines of ensemble performance is associated with the development of academic orientation in the interpretation of folk instruments. The main means of fine transmission of the figurative structure of the performed music is the timbre-register palette, original factual finds and the use of a wide range of sound retrieval techniques. An interesting experience of expanding the expressive possibilities of arrangement was the search for timbre identity of folk instruments - Russian (domra, balalaika) and Iranian (tar, setar), in the creation of the ensemble "Skaz".

In particular, to speak of their kinship, belonging, in accordance with the generally accepted scientific classification of musical instruments, to a group of stringed plucked (chordophones) allows. However, the similarity of constructive elements, the timbre semblance, the version of the origin of domra and the techniques of sound extraction bring them closer together. The sphere of intonation turns out to be completely polar: the mobility of the tare and the setar is due to the peculiarities of the structure of the macam - the melodic model with elements of microchromatics, which does not correspond to the European system of the tempered system. Nevertheless, the organological identity manifested in "generalization through timbre" allows one to experiment boldly with Iranian melody, without interfering with the microamatics of the maqam. Another direction in the field of ensemble performance is directly related to the ancient layer of Russian culture - buffoonery. However, representatives of this current have only internal outlines of this phenomenon of national culture. Russian folk instruments are used as symbols of folk musical art that are stable in the minds of consumers of mass culture, in which one can see signs of speculation in the values of truly popular culture. This approach was also reflected in the means of arrangement, where the virtuosity and installation of external effects comes to the fore. This involves the use of fairly primitive instrumental solutions. At the head of all pseudo-artistic decisions is commercialization, and not a "new look" at Russian folk instruments, as declared by the adepts of this direction.

\section{References}

1. Sharabidze, K.B. (2012) Sovremennye problemy obucheniya igre na narodnykh muzykal'nykh instrumentakh: teoriya i praktika (na materiale uchebno-vospitatel'noy raboty v klasse domry) [Modern problems of learning to play folk music instruments: theory and practice (a case study of teaching and educational work in the class of domra)]. Pedagogy Cand. Diss. Moscow.

2. Famintsyn, A.S. (1995) Skomorokhi na Rusi [Buffoons in Russia]. 2nd ed. St. Petersburg: Aleteyya. pp. 315-535.

3. Belkin, A.A. (1975) Russkie skomorokhi [Russian buffons]. Moscow: Nauka.

4. Conen, W.G. (1994) Tretiy plast: novye massovye zhanry v muzyke XX veka [The third layer: new mass genres in the music of the 20th century]. Translated from English. Moscow: Muzyka.

5. Sargent, W. (1987) Dzhaz: Genezis. Muzykal'nyy yazyk. Estetika [Jazz: Genesis. Musical language]. Translated from English. Moscow: Muzyka. 